\title{
IMPACTOS AMBIENTAIS NA PAISAGEM PROVOCADAS PELAS ATIVIDADES CANAVIEIRAS NOS MUNICÍPIOS DE TUPÃ A BASTOS, SÃO PAULO
}

\section{Leonice Seolin Dias ${ }^{1}$}

Resumo: O presente trabalho é um relato de observações dos impactos ambientais causados pela monocultura canavieira, de 2003 a 2012, nos trechos das estradas vicinais ligando os municípios de Tupã a Bastos e Bastos até a SP-425 (Rodovia Assis Chateaubriand). O objetivo deste trabalho é apresentar, por meio de fotografias, alguns impactos ambientais que podem ser percebidos por intermédio da paisagem em área de plantio de cana-de-açúcar. Para amenizar os impactos com relação às queimadas, entendemos que a colheita mecanizada é uma das alternativas, uma vez que a queimada utilizada para a colheita manual é um dos principais fatores que causam danos ao Meio Ambiente.

Palavras - chaves: Cana-de-açúcar. Monocultura. Impactos ambientais.

\section{INTRODUÇÃO}

$\mathrm{Na}$ contemporaneidade observamos uma grande preocupação ambiental, que deriva das transformações provocadas pelas atividades humanas, uma vez que tais mudanças podem ser verificadas por meio das alterações ambientais globais.

\footnotetext{
${ }^{1}$ Doutoranda em Geografia, Universidade Estadual Paulista - UNESP, Presidente Prudente, SP (nseolin@gmail.com).
} 
As atividades econômicas alteram 0 meio ambiente, pois o homem extrai recursos naturais para sua sobrevivência. A mineração e a agricultura, junto com a exploração florestal, a produção de energia, os transportes, as construções civis (urbanização, estradas, etc.) e as indústrias básicas (químicas e metalúrgicas) são os causadores de inúmeros impactos ambientais negativos.

Segundo o Conselho Nacional do Meio Ambiente (CONAMA) ํo 001/86, 23/01/1986, os impactos ambientais são definidos como:

[...] quaisquer alterações nas características físicas, químicas ou biológicas do ambiente, causadas por qualquer forma de matéria ou energia resultante das atividades humanas, e que possam, direta ou indiretamente, afetar a saúde, segurança e o bem-estar da população, as atividades econômicas e sociais; a biota; as condições estéticas e sanitárias do meio ambiente e a qualidade dos recursos ambientais.

O impacto ambiental é a alteração no meio ou em algum de seus componentes por determinada ação ou atividade. Essas alterações precisam ser quantificadas, pois apresentam variações relativas, podendo ser positivas ou negativas, grandes ou pequenas (LIBONI; CEZARINO, 2012).

Dentre as várias atividades econômicas causadoras de impactos ambientais no Brasil, atualmente, destacamos a agroindústria com cultivo e exploração da cana-deaçúcar em plena expansão. Macedo (2005), afirma que:

[...] a expansão da cana-de-açúcar nos últimos 25 anos ocorreu na região CentroSul do Brasil, em áreas muito distantes dos biomas atuais da Floresta Amazônica, Mata Atlântica e Pantanal. Entre 1992 e 2003, no Centro-Sul, a expansão deu-se quase totalmente $(94 \%)$ nas propriedades rurais já exploradas; novas fronteiras agrícolas foram muito pouco envolvidas. Em São Paulo, o crescimento das áreas cultivadas com cana de açúcar ocorreu com a substituição de outras culturas e pastagens ou áreas de mata.

O Brasil, devido à disponibilidade de terras cultiváveis, é atualmente considerado o maior produtor mundial de cana-de-açúcar e seu cultivo é praticado em quase todos os Estados brasileiros. Segundo o Instituto Brasileiro de Geografia e Estatística - IBGE (2009), esta cultura ocupa aproximadamente uma área de 10 milhões 
de hectares cultivados na safra 2008/2009, produzindo cerca de 650 milhões de toneladas de cana, com perspectivas de continuar se expandindo.

Sendo assim, Liboni e Cezarino (2012) ressaltam que os impactos do setor sucroalcooleiro no meio ambiente incluem:

[...] os efeitos na qualidade do ar e no clima global, no uso do solo e biodiversidade, na conservação do solo, nos recursos hídricos e no uso de defensivos e fertilizantes. O etanol, em comparação com o petróleo e seus derivados, apresenta baixa toxidez e elevada biodegradabilidade, fatores da maior importância no caso de derramamentos acidentais e vazamentos de combustível em costas litorâneas, solo, águas superficiais e subterrâneas. Isso quer dizer que, em caso de acidentes, os impactos ambientais do etanol são substancialmente menores e a recomposição do meio ambiente ocorre mais rapidamente em comparação com os combustíveis fósseis.

Zoratto (2006), também, afirma que o cultivo da cana-de-açúcar tem como principais impactos ambientais:

...a erosão e compactação do solo, os efeitos dos agrotóxicos sobre o solo, rios e lençóis freáticos, os efeitos nocivos que pode causar à atmosfera e incômodos à população durante sua colheita por queimada, além de danos causados à fertilidade do solo. Além dos fatores citados acima, existe o problema com biomassa residual do cultivo de cana-de-açúcar e também o empobrecimento da fauna e flora em geral, devido aos impactos sobre os seres vivos que estão envolvidos com a expansão da monocultura da cana.

Ainda, pode causar: redução da diversidade de espécies, poluição do ar por fumaça e material particulado, devido ás queimadas; aumento na velocidade do vento, devido ao desmatamento, e contaminação do agricultor devido à utilização incorreta de agrotóxicos. Além disso, também podemos mencionar que esta monocultura pode causar severas modificações na paisagem em escala regional. (Cf. Manual de Impactos Ambientais, 2012).

Para Bertrand (2004), a paisagem não é a simples adição de elementos geográficos disparatados. É, em uma determinada porção do espaço, o resultado da combinação dinâmica, portanto instável, de elementos físicos, biológicos e antrópicos que, reagindo dialeticamente uns sobre os outros, fazem da paisagem um conjunto único e indissociável, em perpétua evolução. E, para Tricart (1982), é uma porção perceptível a 
um observador onde se inscreve uma combinação de fatores visíveis e invisíveis e interações as quais, num dado momento não percebemos, senão o resultado global.

Já para Freire (2010):

[...] quando se fala de paisagem estamos falando não de uma natureza "natural", intocável, mas sim de uma natureza antropizada, que passou por processos de alterações significativas devido à interferência humana. Para tanto, damos direcionamento às alterações espaciais decorrentes das atividades econômicas e os usos do solo. Assim, a paisagem é o resultado material de interações entre processos físicos, processos ecológicos, processos sociais e processos culturais.

Como se sabe, o homem tem necessidade de ocupar espaços naturais, transformando-os para extrair deles energia e insumos ou para urbanizá-los. A transformação da paisagem natural em cultural proporciona a base para a manutenção do sistema econômico, gerando, antagonicamente, impactos que precisam ser conhecidos e estudados (REFOSCO, 1996).

Para Corrêa e Rosendahl (2004), a paisagem natural está sendo submetida a uma transformação nas mãos do homem, o que é para nós o fator morfológico mais importante. Por meio de suas culturas faz uso das formas naturais, em muitos casos alterando-as, em alguns destruindo-as.

Estes autores ainda ressaltam que todas as paisagens possuem significados simbólicos porque são produtos da apropriação e transformação do meio ambiente pelo homem.

Destacamos que a utilização da paisagem neste trabalho não se faz pela abordagem da paisagem como objeto de estudo, mas a utilização da paisagem como ferramenta de análise, especificamente para a análise da sustentabilidade do desenvolvimento local da área observada. A paisagem como ferramenta é material, é o que se vê, mas por meio dessa materialidade podemos observar subjetividades (FREIRE, 2010).

Já a fotografia, desde o seu aparecimento, entrou na paisagem. Sua invenção, consecutiva à valorização do quadro pictural, veio para contribuir na renovação de um sistema de representação em mutação. A fotografia não tomou unicamente o lugar da pintura, ela, ao mesmo tempo, modificou as especificidades operatórias, o caráter do dispositivo de artealização. Nossa sensibilidade em relação aos lugares foi afetada. 
Nossa cultura paisagística passou a ser informada de maneira diferente. A qualidade do nosso olhar se modificou (PASSOS, 2004).

Além do mais, afirma-se que a fotografia assume grande relevância na análise geográfica do espaço e suas dinâmicas por instaurar a possibilidade de uma (re)leitura permanente e atenta aos processos de mutação da paisagem. Mesmo que a fotografia capte um instante, uma apreensão paralisada de um momento, ela se abre para as comparações de maneira didática. A fotografia antiga carrega elementos da memória dos lugares/das paisagens, seja ela composta por cenários marcadamente urbanos ou rurais entre os extremos da artificialização da natureza. Por outro lado, a fotografia mais recente registra os acontecimentos do agora e permite refletir sobre o conjunto de fatores que trouxeram as mudanças em relação ao que passou.

De acordo com Lindo e Souza (2012):

[...] o uso da fotografia se justifica pelo fato dela conter um conjunto de objetos que os olhos alcançam e identificam. Temos muito claro que apenas a captura de uma imagem não é suficiente para explicar uma realidade, pois se trata de uma representação estática, uma "fração do espaço" que nossa vista alcança. Analisar a paisagem a partir dos pares dialéticos imediato/mediato, mudança/permanência, forma/conteúdo é de fundamental importância para se reconhecer aspectos inerentes às relações sociais e ir para além da descrição.

Nesse sentido, há concordância com a afirmação de Kossoy (2000, p. 132) citando Souza (2010) para quem "fotografia é memória e com ela se confunde". Seguindo a reflexão, temos em Barthes o seguinte:

[...] a fotografia instaura [...] não uma consciência do estar aqui do objeto (o que qualquer cópia poderia fazer), mas a consciência do ter estado aqui. Trata-se, pois, de uma nova categoria de espaço-tempo: local-imediata e temporalanterior; na fotografia há uma conjunção ilógica entre o aqui e o antigamente. (BARTHES, 1990, p.36, grifos do autor, apud SOUZA, 2010.).

Portanto, o uso da imagem fotográfica é relevante para a análise das transformações da paisagem porque instaura uma leitura dinâmica do espaço geográfico em que podemos compreender o jogo de relações e as múltiplas determinações que levaram às mudanças e permanência deste ou daquele elemento. Ao tratarmos de impactos ambientais como alterações bruscas nas dinâmicas de certos elementos da 
natureza e que geram efeitos negativos para a sociedade, o uso desse recurso torna-se, no mínimo, didático.

Nesse sentido, adotamos uma proposta inspirada em Passos (2008) com a sua "geo-foto-grafia" da Raia Divisória São Paulo-Paraná-Mato Grosso do Sul. Certos de que não podemos desenvolver um trabalho mais pormenorizados diante das limitações de espaço exigidas para um artigo dessa natureza, então procuraremos apresentar neste texto uma análise da dinâmica da paisagem, considerando uma observação da paisagem local de maneira concreta, menos teórica, na medida que a mesma é um elemento constituído de atributos físicos, biológicos e antrópicos, com uma dinâmica própria.

\section{A EXPANSÃO DA PRODUÇÃO DE CANA NO OESTE PAULISTA}

A região Sudeste, mais especificamente o interior paulista, destaca-se pela expressiva produção da cana-de-açúcar, sendo também uma das regiões mais desenvolvidas do país. No Estado de São Paulo, uma região tem chamado atenção pelo crescimento exacerbado do plantio de cana-de-açúcar - o Oeste Paulista, em virtude de ser uma das últimas áreas viáveis disponíveis no estado de São Paulo. Outras áreas tradicionais do monocultivo canavieiro (Sertãozinho, Ribeirão Preto, Jaú, etc.) já não representam mais uma expansão relevante. O Estado de São Paulo abriga 169 unidades sucroalcooleiras, concentrando mais de $60 \%$ de toda a produção nacional de etanol (LERAYER, 2009; ÚNICA, 2012; BELLACOSA, 2012).

Estudos sobre a expansão das áreas plantadas com a cultura canavieira no Estado de São Paulo revelam que a região de Presidente Prudente está entre as grandes produtoras de cana-de-açúcar (COELHO et al., 2007). Ressaltamos que essa expansão tem causado modificações na paisagem, trazendo uma nova configuração territorial para a região, alterando assim as relações entre campo e cidade, e promovendo novas demandas sociais e econômicas para a região.

Atualmente o Estado continua a direcionar políticas específicas para expansão da cultura canavieira em várias regiões do país, entre elas a região de Presidente Prudente. Assim, está ocorrendo um acelerado processo de expansão dessa monocultura na região. 


\section{DINÂMICA DA PAISAGEM: UM RELATO DE EXPERIÊNCIA...}

Atualmente, dependendo da época do ano, as grandes extensões da monocultura cobrem o campo ora por "desertos amarelados", ora por "mares verdes" ou imensas áreas avermelhadas devido o preparo do solo para o plantio da cana, expandido e incorporando cada vez mais hectares. Nos dias atuais, às margens das rodovias notase que as árvores estão desaparecendo, substituídas por canaviais. A pecuária perde espaço em relação às extensões de terra que antes eram destinadas a essa atividade, para dar lugar aos canaviais (Figura 1).

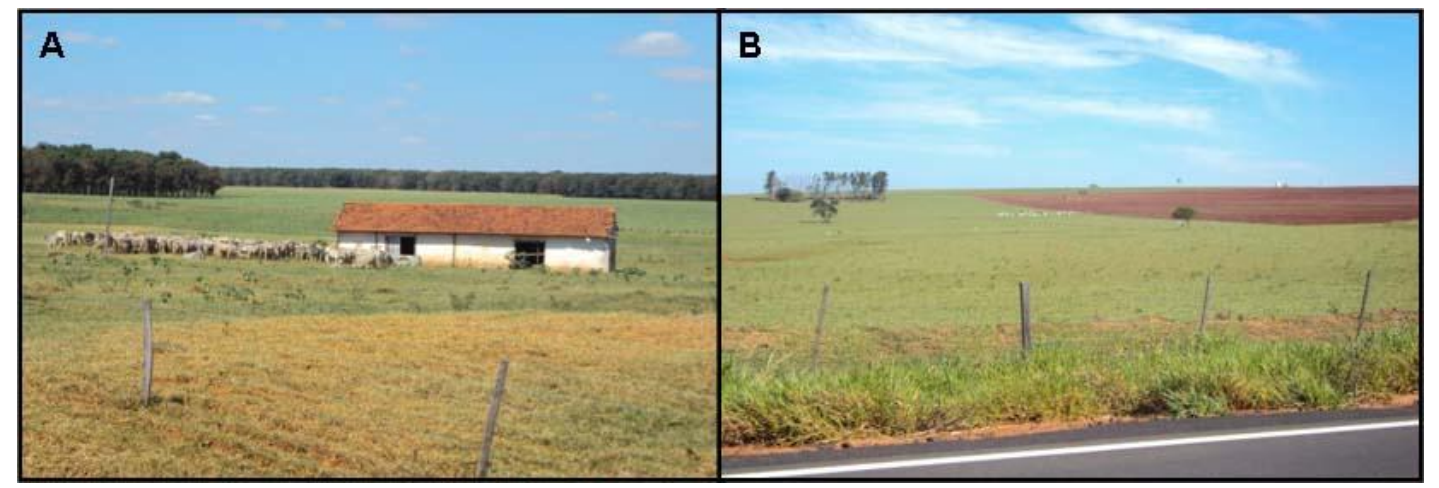

Figura 1. A) Propriedade rural com criação de gado e ao fundo plantio de cana;

B) Área de pastagem perdendo espaço para cana. Fonte: Seolin Dias (2012).

Destacamos, ainda, que uma das formas mais tradicionais de realizar a colheita da cana é a manual. Para que essa pratica se realize, é preciso que se faça a queima prévia, que compreende o uso do fogo para eliminar as folhas e pontas da cana. Quando é realizada esta prática de queimada, podendo-se ver, de longe, um clarão ou nuvens negras de fumaça esquadrinhando o céu das noites. E, quando as queimadas são realizadas próximas às rodovias, ouve-se até o "estalar da queima". No dia seguinte à queima, o corte da cana é realizado pelos trabalhadores, e o que se pode ver é uma paisagem negra e no meio dela uma mistura de fuligem e gente. Além disso, é possível ver animais mortos, moribundos ou abalados pelo fogo (Figura 2). 


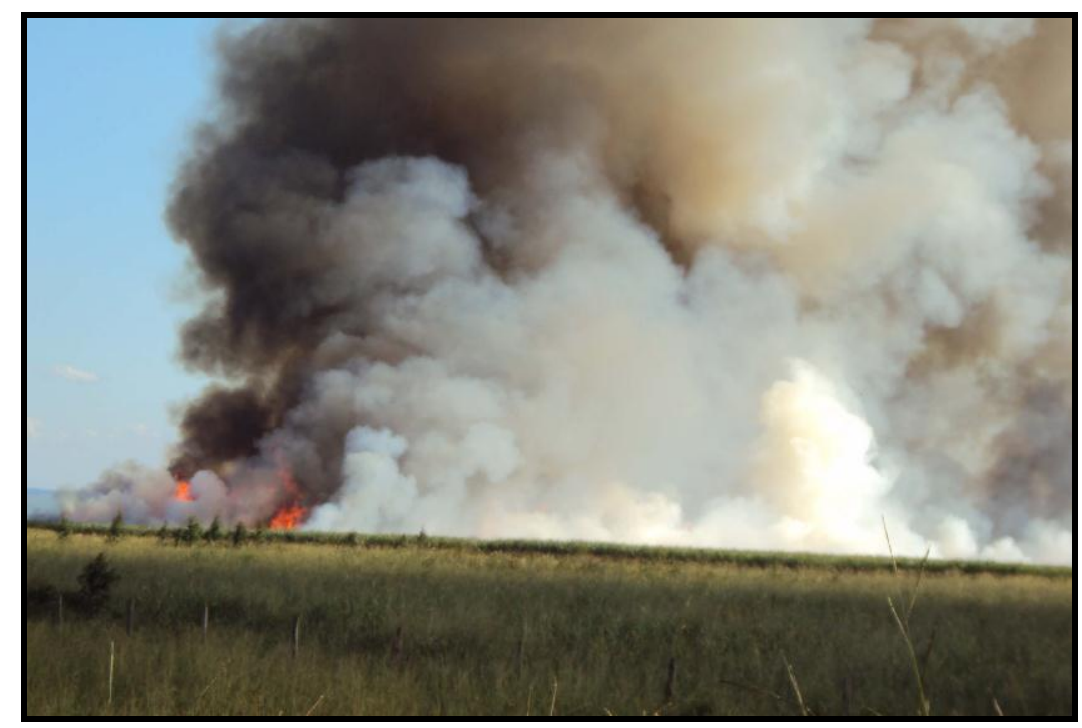

Figura 2. Queima da palha da cana-de-açúcar. Fonte: Seolin Dias (2012).

A maioria do transporte da cana é realizada em rodovias e pelos caminhões chamados "bitrens", que circulam pelas rodovias em baixa velocidade, podendo causar acidente de trânsito e lançando palhas nos ares (Figura 3).

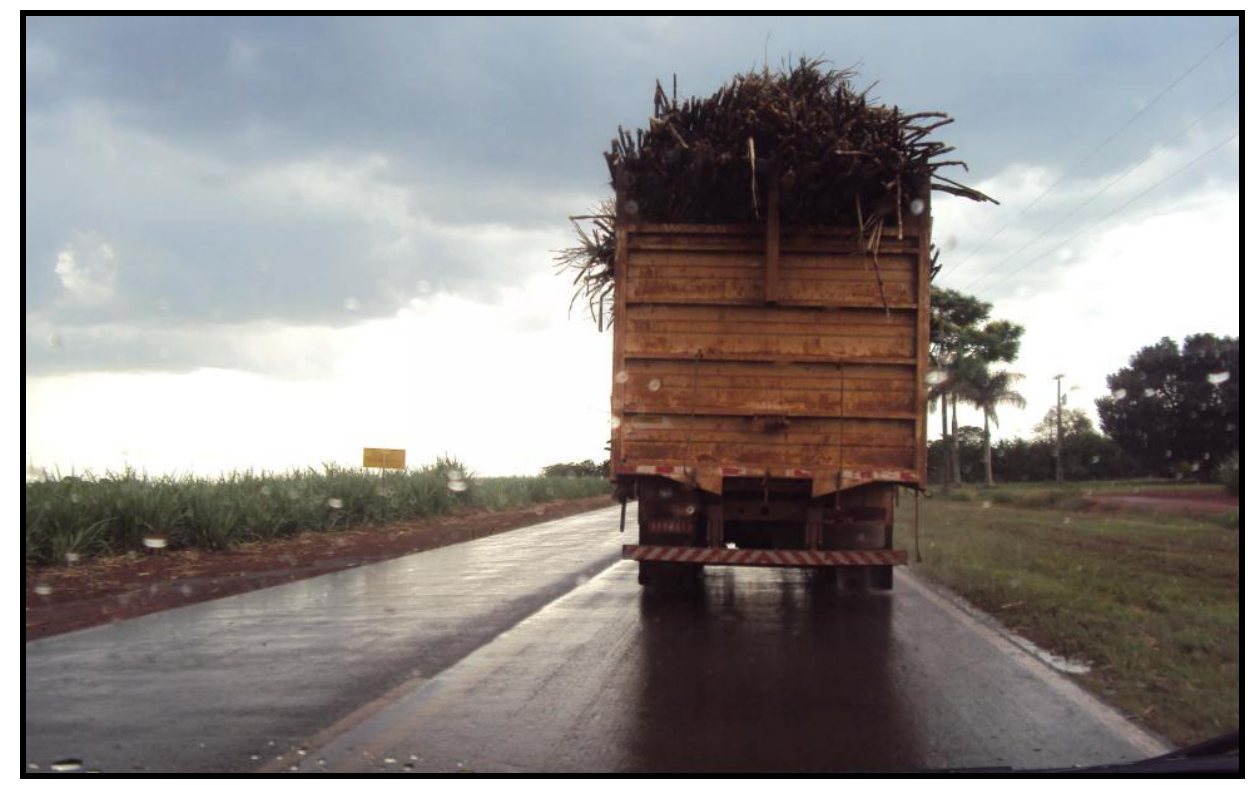

Figura 3. Trafego de caminhão transportando cana-de-açúcar em baixa velocidade. Fonte: Seolin Dias (2012).

Diante de tais cenários, concordamos com Vieira (2011), quando ressalta que: 
O grande problema é que neste amargo regresso da cana se perpetua a mesma história da degradação social e da depredação ambiental já vivida no primeiro ciclo da cultura no país. Ela só não é igual hoje porque os métodos são diferentes, as tecnologias mais avançadas, a degradação mais profunda, a amplitude dos empreendimentos bem maiores e os arranjos econômicos compreendem poderosas corporações transnacionais. Em vez de engenhos temos usinas. Mas é o mesmo processo de mercantilização da natureza e da vida.

Nos dias atuais, percorrer a certos trechos da região Oeste do estado de São Paulo pode ser uma viagem entediante. O que se descortina à vista do viajante é apenas uma amarga paisagem, uma vez que as plantações de cana cobrem extensões infinitas.

\section{OBJETIVO}

O objetivo deste trabalho é apresentar, por meio de fotografias, alguns impactos ambientais que podem ser percebidos por intermédio da paisagem em área de plantio de cana-de-açúcar.

\section{PROCEDIMENTO METODOLÓGICO}

\section{Área de estudo}

A paisagem observada de Tupã a Bastos pode ser configurada como um mosaico formado de áreas altamente antropizadas, destacando-se: áreas rurais destinadas principalmente às atividades agropecuárias (criação de gado e cana-deaçúcar), estreitas faixas de matas ciliares, remanescentes florestais perturbados e isolados, faixas ocupadas pelas redes de alta tensão e rodovias, áreas urbanas, além das áreas de drenagem de alguns córregos.

Quanto à classificação do uso atual da terra, no geral a região é caracterizada por áreas urbanas de uso misto e áreas rurais destinadas principalmente à produção de cana-de-açúcar. 
Os impactos ambientais da atividade canavieira foram observados, no período de 2003 a 2012, nos trechos das estradas vicinais ligando os municípios de Tupã a Bastos e Bastos até a SP-425 (Rodovia Assis Chateaubriand). Nesse percurso está localizada uma usina canavieira e o município de Bastos (Figura 4) apresenta como sua principal atividade econômica a avicultura, objetivando a produção e comércio de ovos e aves.

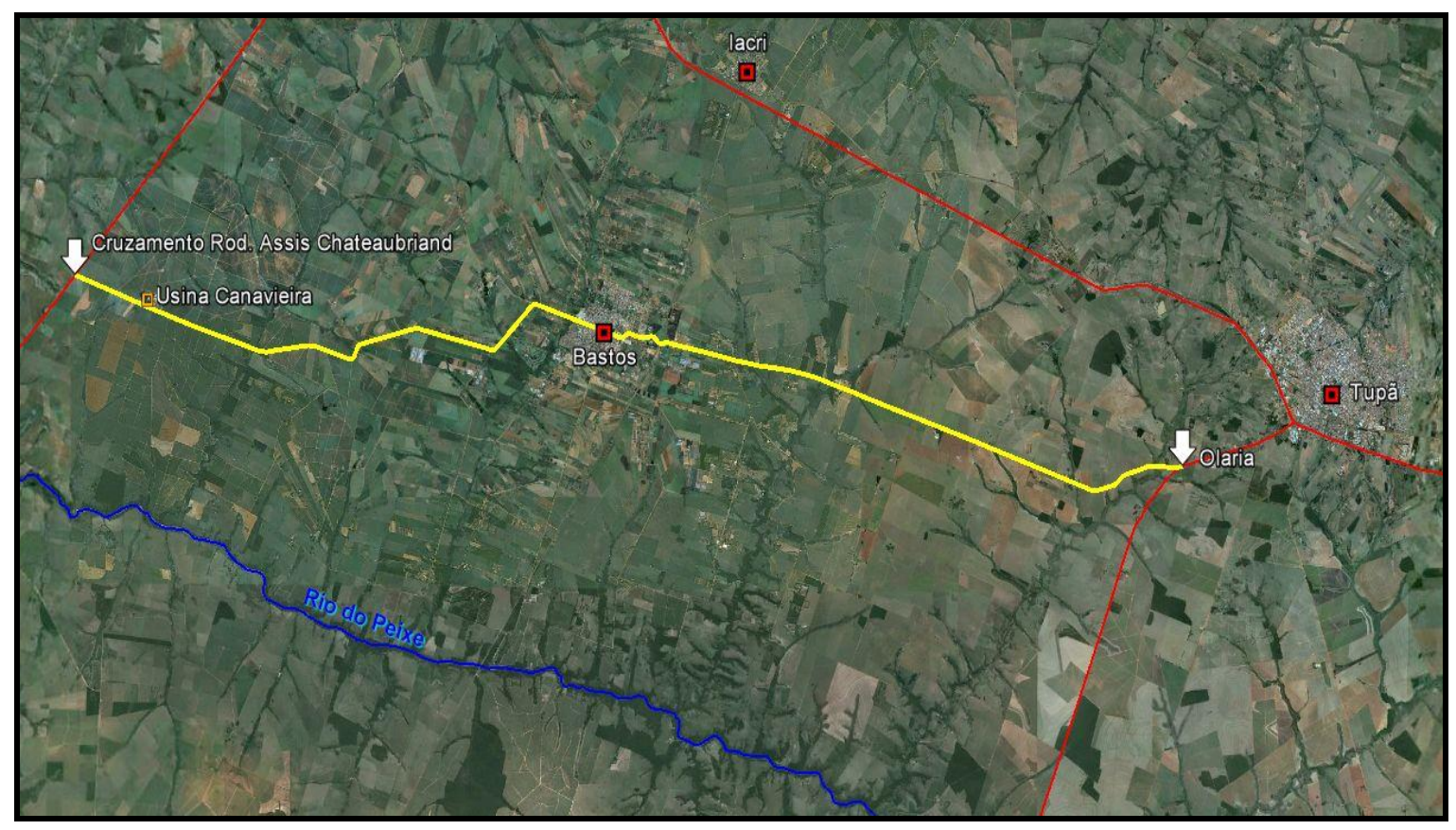

Figura 4. Trajeto das estradas vicinais ligando os municípios de Tupã a Bastos e Bastos a SP425 (Rodovia Assis Chateaubriand). Fonte: Google Earth.

Org. Rafael da Silva Nunes (2012).

No decorrer desses anos notou-se a expansão do cultivo desta monocultura nessa região, que segundo Barbosa (2006):

[...] isto ocorre devido às dificuldades econômicas encontradas por muitos dos pequenos produtores da região em fazer produzir as suas terras, o arrendamento das propriedades para a usina que beneficia esta matéria-prima, apresentou-se como uma alternativa bastante viável, permitindo assim, que aumentasse de maneira vultuosa o cultivo dessa gramínea em extensas áreas, causando impactos sócio-ambientais expressivos.

Ressaltamos que são visíveis as transformações da paisagem às margens das estradas vicinais observadas, uma vez que são nítidas as grandes áreas de pastagens 
que deram lugar ao cultivo de cana-de-açúcar e, além disso, nota-se a proximidade do plantio no entorno de granjas e da própria cidade e casas de sítios (Figuras 5).

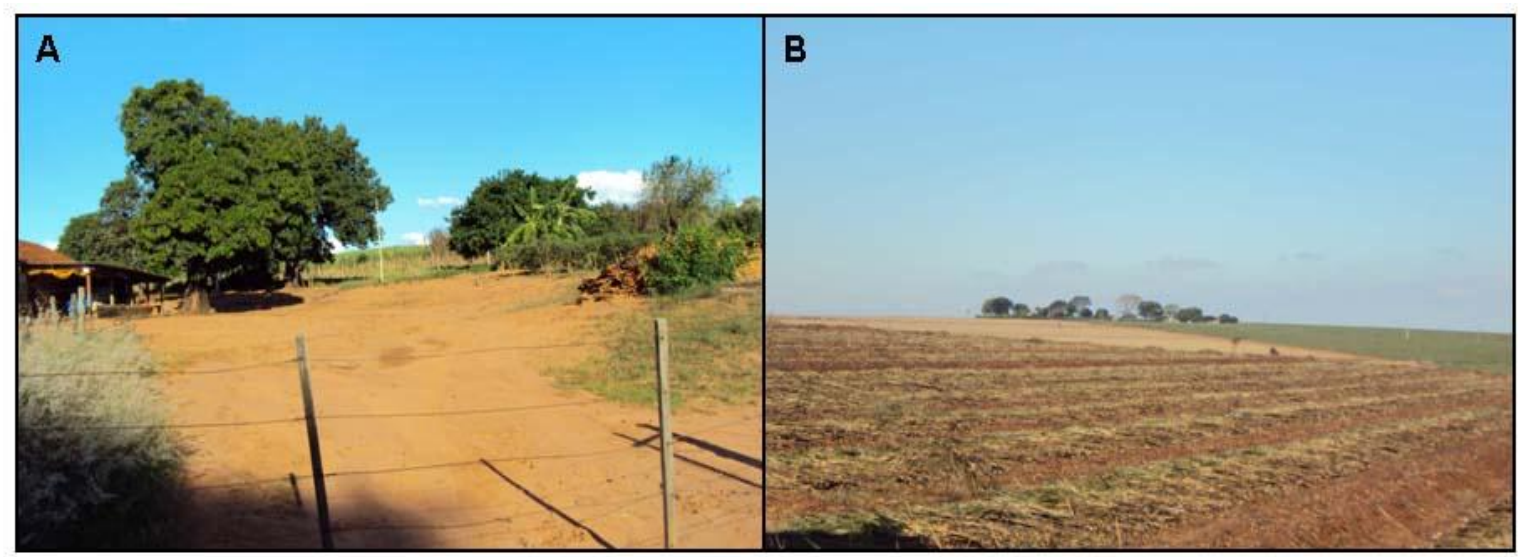

Figuras 5. Expansão do cultivo da cana-de-açúcar: A) Propriedade rural com plantio ao fundo do quintal (proprietário possui 11 alqueires de terra e 10 estão arrendados para o cultivo da cana); B) Outra propriedade rural ocupada quase totalmente com plantio da cana. Fonte: Seolin Dias (2012).

\section{RESULTADOS E DISCUSSÕES}

A seguir apresentamos algumas as fotografias selecionadas, dos impactos ambientais e sua análise, observados nas estradas vicinais Tupã/Bastos, Bastos/SP-425.

Por meio das fotografias se observa uma paisagem antropizada de maneira concreta, na medida em que a mesma é um elemento constituído de atributos físicos, biológicos e antrópicos, com uma dinâmica própria.

Com relação às fotografias, segundo Ferronato (2012) citando Lima e Barthes, a ação humana na paisagem não se sintetiza apenas ao momento presente, mas reflete a multiplicidade de camadas superpostas ao longo do tempo, evidenciando potencialidades de experiências.

Diante disso, a seguir estão apresentamos alguns fotos dos impactos ambientais observados neste trabalho. 


\section{Periódica Eletrânica Fórum Ambiental}

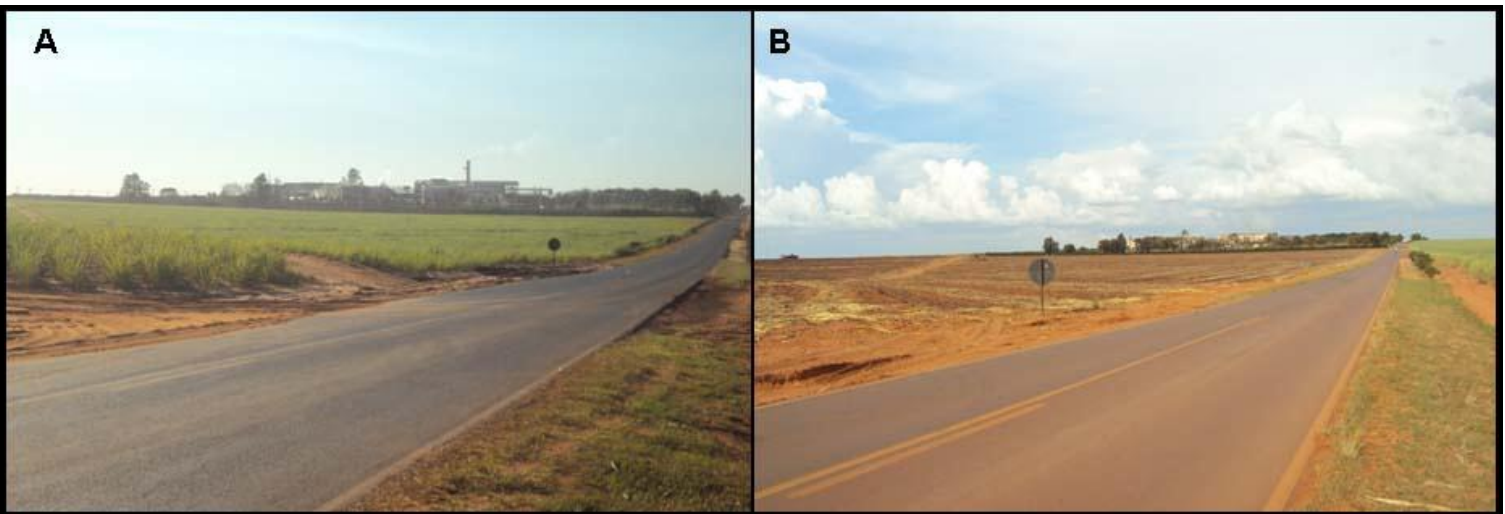

Figura 6. Vista parcial da usina ao fundo, antes do corte da cana; B) Vista parcial da usina ao fundo, após a prática da queimada e do corte da cana-de-açúcar.

Fonte: SEOLIN DIAS (2012).

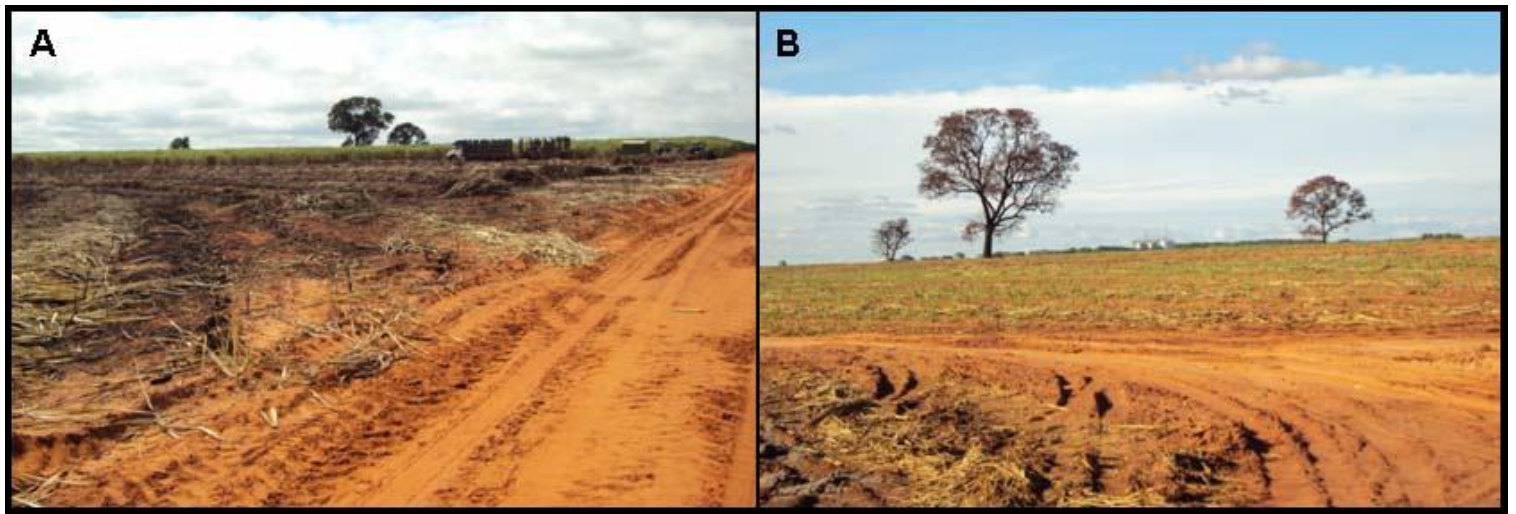

Figura 7. A) Resultado da ação do fogo em parte canavial e corte da cana pelos trabalhadores; B) A vegetação apresenta vestígios da queimada. Fonte: Seolin Dias (2012). 

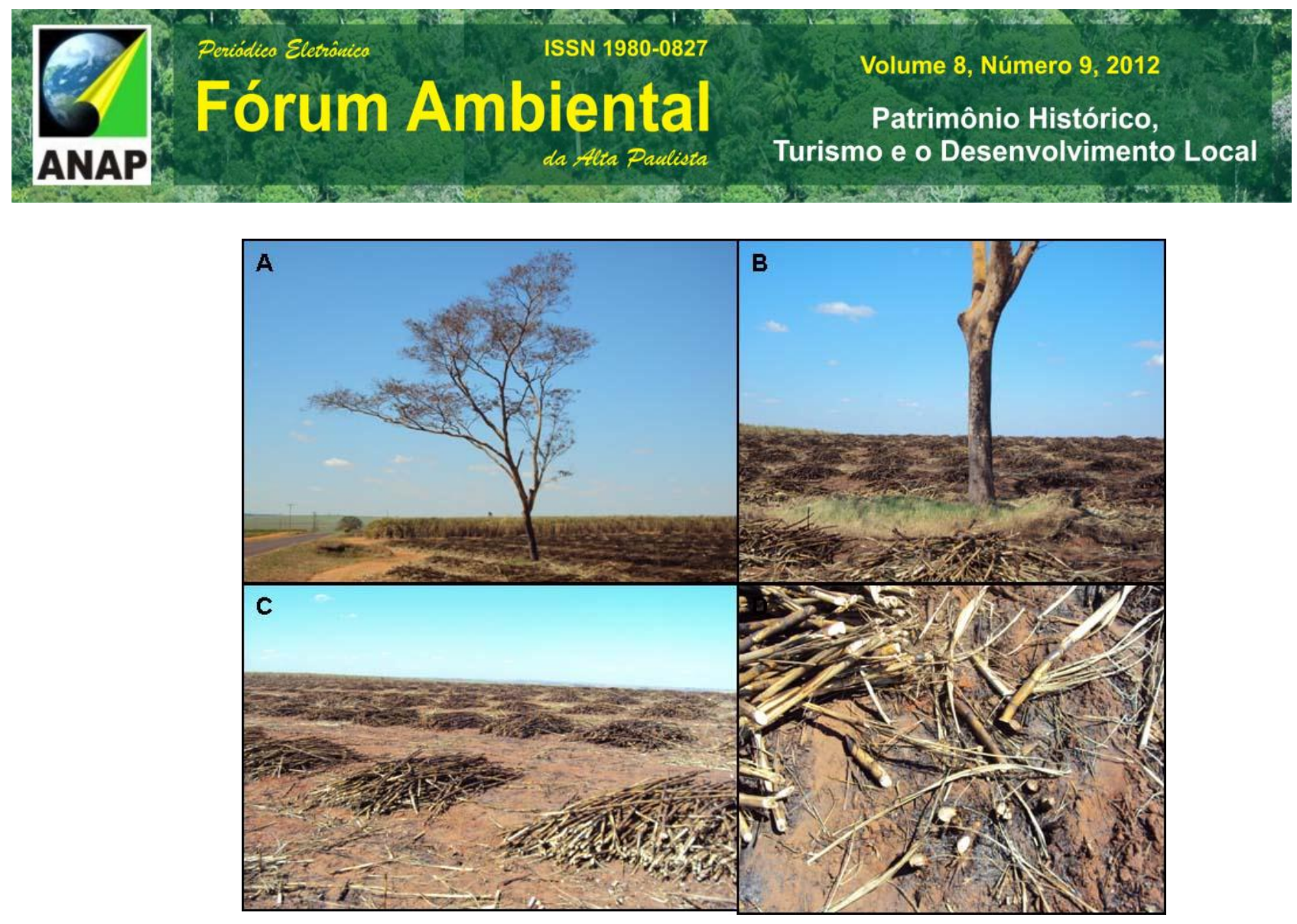

Figura 8. A) Vista do canavial queimado; B) Árvore afetada pelas queimadas que continue subsistindo; C) Cana-de-açúcar para ser transportada para a usina; D) ação do fogo no solo. Fonte: Seolin Dias (2012).

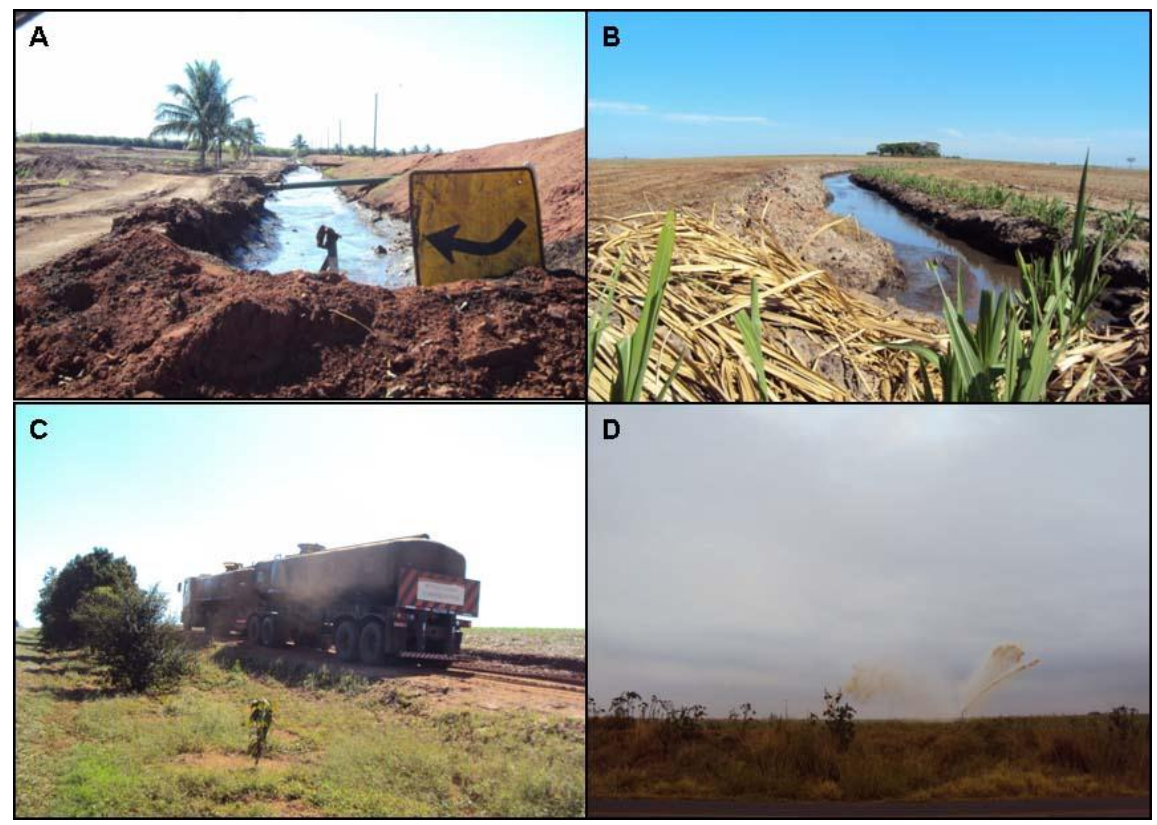

Figura 9. Algumas práticas, adotadas por quase todas as usinas, de aplicação de vinhaça na lavoura de cana. A) vinhaça saindo da indústria; B) Escoamento do resíduo, a céu aberto, diretamente do solo; C) Utilização de caminhão tanque para o transporte do líquido até o campo; D) O emprego da vinhaça na fertirrigação da cana. Fonte: Seolin Dias (2012). 


\section{Des

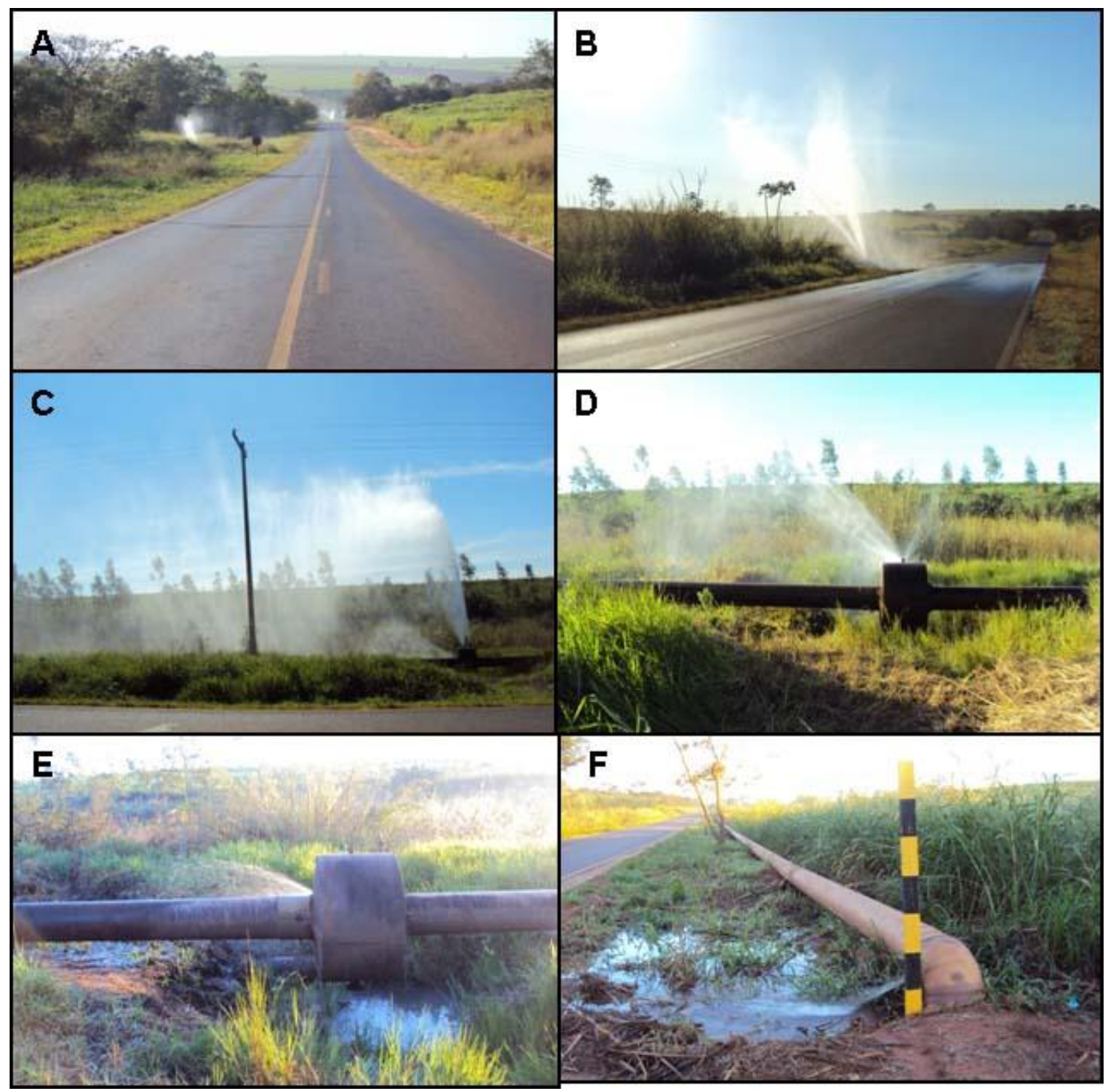

Figura 10. A e B) Vista parcial da estrada vicinal com vazamento de água pela tubulação que transporta água até a usina; C, D, E, E) O desperdício da água em virtude da tubulação mal conservada. Fonte: Seolin Dias (2012).

\section{CONSIDERAÇÕES FINAIS}

A implantação de um grande empreendimento industrial causa impactos que podem ser de ordem econômica, social ou ambiental. Quando está em evidência a instalação de usina de processamento da cana-de-apçucar para produção de açúcar e álcool, é elementar surtir alguns efeitos retratados. 


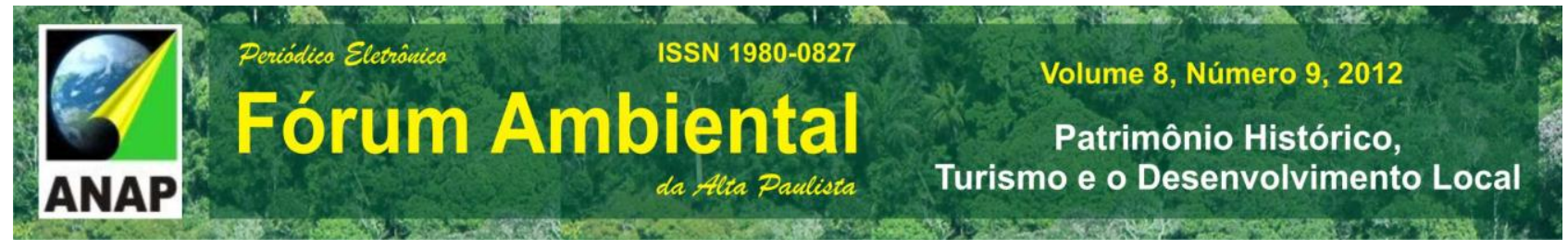

Desta forma, tendo em conta a expansão da cultura da cana-de-açúcar no Oeste Paulista, delimitamos nosso trabalho a duas estradas vicinais (ligando os municípios de Tupã a Bastos e ligando Bastos à SP-425-Rodovia Assis Chateaubriand), procurando conhecer qual a dimensão de alguns impactos ambientais gerados por uma Agroindústria da Cana-de-açúcar na região.

Neste trabalho, retratamos por meio de algumas fotografias, observadas ás margens das estradas vicinais, a ação antrópica no cultivo da cana-de-açúcar e seus efeitos negativos.

Para amenizar os impactos com relação às queimadas nos canaviais, entendemos que a colheita mecanizada é uma das alternativas, uma vez que a queima da palha da cana utilizada para a colheita manual causa danos ao meio ambiente, à saúde das pessoas, e atinge a flora e a fauna.

\section{REFERENCIAS}

BARBOSA, M. A. L. V. Os impactos ambientais causados pela monoculturada cana-deaçúcar no município de Americano doBrasil. 30 f. 2006. Monografia (curso de Geografia Parcelada) Faculdade de Educação e Ciências Humanas de Anicuns (FECHA). Goiás.

BARTHES, R. O óbvio e o obtuso. Rio de Janeiro: Nova Fronteira, 1990.

BELLACOSA, J. M. Expansão dos agrocombustíveis em terras paulistas: estudo de caso em Araçatuba, SP. Disponível em:

http://www.uff.br/vsinga/trabalhos/Trabalhos\%20Completos/Julia\%20Marques\%20Bellaco sa.pdf. Acesso em: out. 2012.

BRASIL. Conselho Nacional do Meio Ambiente. Resolução CONAMA no 001 de 23 de janeiro de 1986. Estabelece as definições, as responsabilidades, os critérios básicos e as diretrizes gerais para uso e implementação da Avaliação de Impacto Ambiental como um dos instrumentos da Política Nacional do Meio Ambiente. Diário Oficial [da] República Federativa do Brasil. Brasília, DF, 17 fev. 1986. Disponível em: < http:// www.mma.gov.br>. Acesso em: 28 out. 2012.

BERTRAND, G. Paisagem e geografia física global. Esboço metodológico. Revista R. RA'E GA, Curitiba: Editora UFPR, n. 8, p. 141-152, 2004. 
COELHO et al. A Sustentabilidade da expansão da cultura canavieira. Cadernos Técnicos da Associação Nacional de Transportes Públicos, v. 6, 2007.

CORRÊA. R. L.; ROSENDAHL, Z. Paisagem, tempo e cultura. Rio de Janeiro: UERJ, 2004.

ESTÊVEZ, L. F. Uso do solo e geo-foto-grafia de PORTO RICO/PR. Revista GEOMAE, v.1, 2 p $.93-109,2010$.

IBGE - INSTITUTO BRASILEIRO DE GEOGRAFIA E ESTATÍSTICA. Levantamento Sistemático da Produção Agrícola. Disponível em:

$<$ http://www.ibge.gov.br/home/estatistica/indicadores/agropecuaria/lspa/default.shtm >. Acesso em: set. 2012.

KOSSOY, B. Realidades e ficções na trama fotográfica. 2.ed. São Paulo: Ateliê Editorial, 2000.

LIBONI, L. B.; CEZARINO, L. O. Impactos sociais e ambientais da industria da cana-deaçúcar. Future Studies Research Journal. v. 4, n. 1, p. 202 - 230, 2012.

LERAYER, A.,et al.Guia do algodão - Tecnologia no campo para uma industria de qualidade. Agosto/2009. Disponível em: < http://www.cib.org.br/pdf/guia_algodao.pdf > acessado em: out. 2012.

LINDO, P. V. F.; SOUZA, R. J. S. A fotografia como instrumento potencializador de políticas públicas: o caso de Mirante do Paranapanema - SP. Disponível em: http://www.dge.uem.br/semana/eixo5/trabalho_44.pdf. Acesso em: set. 2012.

MACEDO, I. C. A Energia da Cana-de-açúcar - Doze estudos sobre a agroindústria da cana-de-açúcar no Brasil e a sua sustentabilidade. Berlendis \& Vertecchia. São Paulo: SP. Única - União da Agroindústria Canavieira de São Paulo, 2005. 231 p.

MANUAL DE IMPACTOS AMBIENTAIS - Orientações básicas sobre aspectos ambientais de atividades produtivas. Disponível em:

<http://www.mma.gov.br/estruturas/sqa_pnla/_arquivos/manual_bnb.pdf>. Acesso em: set. 2012.

PASSOS, M. M. A Raia Divisória: geo-foto-grafia da Raia Divisória. Maringá: Eduem, 2008. 
PASSOS, M. M. A. A paisagem do Pontal do Paranapanema - uma apreensão geofotográfica. Acta Scientiarum. Human and Social Sciences, v. 26, n. 1, p. 177-189, 2004..

REFOSCO, J. L.. Ecologia da paisagem e Sistema de Informações geográficas no Estudo da Interferência da Paisagem na Concentração de Sólidos Totais em Suspensão no reservatório da Usina de Barra Bonita. Dissertação, São Carlos - SP (Mestrado em Engenharia Ambiental) EESC - Escola de Engenharia de São Carlos, 1996.

TRICART, J. Paisagem e ecologia. Inter-Facies: escritos e documentos. São José do Rio Preto: Ed. UNESP, 1982.

ÚNICA. UNIÃO DA INDÚSTRIA DA CANA-DE-ACUÇAR. Disponível em: http://www.unica.com.br/. Acesso em: set. 2012.

VIEIRA, M. A. O amargo regresso da cana-de-açúcar. Disponível em: http://www.semapirs.com.br/semapi2005/site/livro/cd\%20rom/arquivos/09.pdf. Acesso em: set. 2012.

ZORATTO. A. C. Principais impactos da cana-de-açúcar. II Fórum Ambiental da Alta Paulista, 2006. Disponível em:

http://www.amigosdanatureza.org.br/noticias/306/trabalhos/131.AS-9.pdf. Acesso em: set. 2012. 